\title{
EVOLUÇÃO HISTÓRICA DA PREVIDÊNCIA SOCIAL: o sistema previdenciário brasileiro é estável?
}

\author{
Juliana De Oliveira ${ }^{1}$
}

\begin{abstract}
RESUMO: Este artigo pretende contemplar o aparato de consolidação histórica da proteção social, a qual tem origem na natureza humana de ajudar os que enfrentam contingências mundanas que acometem o homem de maneira alheia a sua vontade, sendo transposta do plano subconsciente e intuitivo, ao plano racional e assim, positivado. Desta forma, o homem criou, vagarosamente, instrumentos que foram abarcando o conceito da proteção social em um formato de regulamentos, originando assim a seguridade social, e também, a previdência social, os quais serão analisados no presente artigo.
\end{abstract}

Palavras-chaves: evolução histórica; proteção social; seguridade social; previdência social; contingências.

\section{HISTORICAL EVOLUTION OF SOCIAL SECURITY: Is the Brazilian pension system stable?}

\begin{abstract}
This article intends to contemplate the historical consolidation apparatus of social protection, which originates in the human nature of helping those who face worldly contingencies that affect man in a way that is alien to his will, being transposed from the subconscious and intuitive plane to the rational and thus, positived. In this way, man has slowly created instruments that have covered the concept of social protection in a format of regulations, thus giving rise to social security, as well as social security, which will be analyzed in this article.
\end{abstract}

Keywords: historical evolution; social protection; social Security; social Security; contingencies.

\footnotetext{
${ }^{1}$ Mestre em Direito pela Universidade do Oeste de Santa Catarina (UNOESC), nas Dimensões materiais e eficaciais dos direitos fundamentais, linha de pesquisa Direitos fundamentais sociais: relações de trabalho e seguridade social. Possui Pós Graduação Universidade do Oeste de Santa Catarina em Direito e Processo do Trabalho (2011), Direito e Processo Civil (2012) e Advocacia Civil e Empresarial (2015). Possui graduação em Direito pela Universidade do Oeste de Santa Catarina (2011). Atualmente é Advogada (Oliveira Advogados Associados) e Assessora Jurídica do MUNICÍPIO DE SAUDADES. Atua como docente universitária na Universidade do Oeste de Santa Catarina (UNOESC) nas disciplinas de Direito Previdenciário, Direito Empresarial, Direito Tributário e Direito Internacional.
} 


\section{INTRODUÇÃO}

A partir do presente artigo pretende-se analisar a evolução histórica da proteção social, da seguridade social e da previdência social.

Este trabalho possui como tema a análise da evolução histórica da proteção social, da seguridade social e da previdência social, tem-se como problema de pesquisa demonstrar a existência ou não de estabilidade no sistema previdenciário brasileiro.

Desta forma, tendo como base a constante mutabilidade demográfica da sociedade e assim, consequentemente alterando o equilíbrio atuarial do Estado e este, por sua vez, refletindo na modificação do risco social já consagrado em direitos fundamentais sociais, ensejando a modificação da legislação constantemente.

Neste diapasão, objetiva-se com a pesquisa demonstrar como surgiu a proteção social, além da evolução histórica da seguridade social e da previdência social, além de seus aspectos básicos funcionais e, também, como os fatores socioeconômicos influenciam de maneira direta nas alterações realizadas pela legislação previdenciária.

Para chegar à conclusão serão utilizadas doutrinas jurídicas, periódicos, acervos digitais e a legislação em si, com uma abordagem qualitativa e quantitativa, ante a exposição de dados e estatísticas além de comentários subjetivos pertinentes à matéria.

\section{A PROTEÇÃO SOCIAL}

Não há como abordar o tema da seguridade social, mais especificamente da previdência social, sem esmiuçar os elementos históricos e jurídicos que concretizaram o que em um primeiro momento era tido como mero auxílio voluntário e por vezes, inato ao homem, quando este ajudava o seu semelhante frente os infortúnios da vida humana. Partindo deste pressuposto, vislumbra-se um breve apanhado do fator gerador da seguridade social e da previdência social, que é o que denominamos de proteção social.

Ibrahim (2015) menciona que desde os tempos remotos, o homem tem se adaptado, no sentido de reduzir os efeitos das adversidades da vida, como fome, doença e velhice, ou seja, a preocupação com os infortúnios da vida tem sido uma constante da humanidade. Ou seja, mesmo quando inexistiam legislações que tratassem especificamente desta curatela ou tutela 


\section{EVOLUÇÃO HISTÓRICA DA PREVIDÊNCIA SOCIAL: o sistema previdenciário}

brasileiro é estável??

frente às adversidades que incidem na vida humana pelo Estado, por exemplo, já existia uma preocupação pode-se dizer que, inerente à natureza humana, do ser humano pelo ser humano.

É possível afirmar que a proteção social nasceu, verdadeiramente, na família, visto que antigamente as pessoas comumente viviam em largos aglomerados familiares, sendo incumbência dos jovens, além do labor, o cuidado aos idosos e incapacitados ao trabalho. Analiticamente, pode-se afirmar que o homem é um ser qual possui uma necessidade de conviver em sociedade, deixando de lado as especificações técnicas e filosóficas da expressão, apenas em um sentido literal, visto que não é capaz de prever os obstáculos que podem depreciar sua capacidade de se autossustentar, necessitando de auxílio, no caso, em um primeiro plano, da família (IBRAHIM, 2015).

Horvath Jr. (2014, p. 21), afirma que o receio do porvir e a noção de proteção contra riscos sempre se fez presente na história e sempre frequentou os temores humanos e, que este cuidado correlaciona-se com o próprio instinto de sobrevivência humano, sendo que esta visão de proteção é um fruto da natureza humana qual denota um traço individual e/ou familiar de proteção, sendo que as técnicas coletivas de proteção social são importantes visto que por vezes havia inexistência de cumulação de recursos em períodos de necessidade. Ou seja, de modo a complementar o que traz Ibrahim em sua obra, Horvath Junior deixa evidente que o homem necessita de colaboração para garantir de fato sua sobrevivência.

Como se pode extrair da explanação dos dois doutrinadores acima mencionados acerca destas primeiras impressões do surgimento da proteção social, tem-se que este conceito de proteção advinda da família não era por si satisfatória. Nem todas as pessoas eram dotadas de tal proteção familiar e, mesmo quando existia, era por vezes precária, ensejando assim, a necessidade de auxílio externo, com natureza eminentemente voluntária de terceiros, muito incentivada pela Igreja, ainda que tardiamente, vindo o Estado a assumir alguma ação por volta do Século XVII com edição da Lei dos Pobres (IBRAHIM, 2015).

De modo coerente, redige Horvath Jr (2014, p.22), que para combater esta indigência, foram desenvolvidos inúmeros modelos de proteção individual e social, como a beneficência, assistência pública, socorro mútuo, seguro social e seguridade social. Contudo, o seguro social surge apenas após a revolução industrial e a seguridade social, qual é um conceito mais amplo, abrange medidas que também surgiram apenas em momento posterior aos demais modos de proteção social. 
Desta forma, convém ressaltar que a beneficência está relacionada à proteção social motivada pelo caritas, o amor ao próximo, onde a igreja criava hospedagens anexas aos templos, auxiliando órfãos, anciãos, inválidos e doentes, tudo de modo filantrópico, visto não ser direito nem mesmo um dever. A assistência realizada pelos indivíduos (assistência privada) é um fim de toda a coletividade, diferenciada da filantropia por não ser puramente altruísta, mas sim, de profilaxia social (HORVARTH JR, 2014).

Sob este tema, Ibrahim (2015, p. 2) narra que a adoção de novas formas de proteção familiar foram necessárias, principalmente pela desagregação social, qual aviltava e ainda debilita a mais antiga forma de proteção social, a advinda da família. Ainda, diz que dessas novas formas, como o auxílio voluntário, estes preencheram constantemente a lacuna da proteção familiar, sendo tão importantes hoje, como foram no passado, e além da assistência espontânea, a sociedade viu surgirem também os primeiros grupos de mútuo, igualmente os de origem livre, sem intervenção estatal, nos quais um conjunto de pessoas com interesse comum reunia-se, visando à cotização de valor certo para o resguardo de todos caso houvesse algum infortúnio.

Assim, tem-se que a primeira etapa da proteção social foi a da assistência pública, fundada na caridade e em sua maior parte, conduzida pela Igreja, sendo apenas em momento posterior substituída pelas Instituições Públicas, onde o indivíduo em situação de necessidade - desemprego, doença e invalidez - socorria-se da caridade dos demais membros da comunidade, onde não havia um direito subjetivo do necessitado à proteção social e sim de mera expectativa de direito, visto que o auxílio da comunidade ficava condicionado à existência de recursos destinados à caridade (SANTOS, 2016).

Na concepção do que se narrou anteriormente, em Roma, Horvarth Jr (2014, p. 22) relata que existiram as associações denominadas collegia ou sodalitia, com destaque os collegia tenuiorum, que, mediante contribuições de seus associados, tinham por escopo assegurar a sepultura e as despesas dos funerais dos sócios, criando entre seus membros, uma solidariedade de interesses e necessidades. Ainda, na Idade Média, na Germânia, encontramos as associações chamadas de guilras, que tinham como finalidade conceder assistência a seus associados em caso de doença e prover as despesas funerais de seus membros.

Importante ressaltar que Passos (2013, p. 44), menciona que a partir da idade média estes socorros aos necessitados ultrapassaram os limites dos grupos primários, atingindo certa apresentação institucional, embora especialmente vinculadas à igreja, por meio de orfanatos, 


\section{EVOLUÇÃO HISTÓRICA DA PREVIDÊNCIA SOCIAL: o sistema previdenciário}

brasileiro é estável??

asilos e hospitais, mantidos por donativos dos fiéis mais abastados, ante a obrigação judaicocristã de caridade. Ainda de acordo com o autor, também surgiram tentativas de proteção comunitárias entre os próprios trabalhadores, como os grêmios, confrarias e associações.

Não obstante, a criação dos primeiros seguros marítimos é frequentemente citada no estudo da evolução social, muito embora seu escopo tenha sido muito mais voltado à proteção da carga do que das pessoas envolvidas, era a ideia do seguro que se aprimorava (IBRAHIM, 2015). Ainda no teor das palavras do autor, com o tempo, notou-se a assunção por parte do Estado, de alguma parcela de responsabilidade pela assistência dos desprovidos de renda até, finalmente, a criação de um sistema estatal securitário, coletivo e compulsório, onde se esgotava a prevalência de conceitos liberais, qual apenas trazia intervenção mínima do Estado em áreas fundamentais, como organização jurídica e segurança.

Dessa maneira, é notória a evolução do conceito de proteção social ao passar das décadas e séculos, onde primordialmente era algo meramente advindo da manifestação de vontade do indivíduo em prestar auxílio aos seus semelhantes quando nem mesmo algum consenso prévio havia sido estabelecido perante a sociedade. Exemplo disso, é a inserção da participação Estatal, ou então, de seus primeiros passos na tomada de intervenção nesta seara, quando na sociedade industrial, como traz Horvarth Jr. (2014, p. 22) surgiu o seguro social em decorrência da revolução social, criando a figura do trabalhador assalariado, qual necessitava de proteção contra acidente do trabalho, doença, invalidez e morte, contudo, excluindo os não trabalhadores.

No começo do século XVII, na Inglaterra, mais especificamente no ano de 1601, é editada a Lei dos Pobres (Poor Law Act), a qual foi editada pela Rainha Isabel, sendo considerada a primeira lei que discerne acerca da assistência social. Esta lei encarregava as paróquias de desenvolver programas para alívio da miséria, quais se destinavam a dar proteção às crianças pobres, proporcionar trabalho aos desempregados e amparo aos idosos e inválidos, sendo os programas financiados por uma taxa obrigatória criada por essa Lei (HORVARTH JR, 2014).

Importante complementar que até o século XVIII, não havia a sistematização de qualquer forma de prestação estatal, pois, de modo geral não era atribuído ao Estado o dever de dar assistência aos necessitados. Contudo, encontra-se a exceção quando do registro na história 
da Poor Law, editada em 1601 na Inglaterra, qual constituía contribuição obrigatória para fins sociais, com intuito assistencial (CASTRO; LAZZARI, 2015).

Em 1662 foi implantado na Inglaterra o Decreto de Domicílio (Act of settlement), que tanto impedia as paróquias de livrarem-se de seus pobres e obrigando estes mesmos a não mudarem de domicílio, como evitava que as paróquias mais organizadas no atendimento aos necessitados fossem invadidas por uma massa de indigentes profissionais. Contudo, em 1795 o Decreto de domicílio foi superado, pois restringia a mobilidade do indivíduo a sua comunidade natal e por favorecer apenas os proprietários rurais com disponibilidade de trabalhadores locais, permitindo assim que estes buscassem melhores opções de trabalho fora de suas cidades, atendendo assim aos anseios industriais (PASSOS, 2013).

Entrementes, de acordo com Horvarth Jr (2014, p. 24), com a Revolução Francesa de 1789, surgiu a Declaração dos Direitos do Homem e do Cidadão, adotada pela Assembleia Constituinte em 27 de agosto de 1789 e votada definitivamente em 2 de outubro de 1789, prevendo esta, um modelo de proteção social de caráter público e contributivo. Não obstante, em 1789, com a primeira edição desta declaração, a proteção social caminhou para o plano de fundamento estatal e deu os primeiros indícios de contribuição social.

De mesmo modo, Castro e Lazzari (2015, p. 7) fortalecem o que afirma Horvarth Jr. ao discorrerem que a primeira vez em que nota-se uma mudança na concepção da proteção ao indivíduo ocorre na Declaração dos Direitos do Homem e do Cidadão em 1789, que inscreve o princípio da seguridade social como direito subjetivo assegurado a todos. Dessa forma, os autores apontam que por este viés, que tal medida deve-se pelo chamado liberalismo político, influenciado por movimentos de trabalhadores, o que vai acarretar a deflagração da ideia de previdência social, pública, gerida pelo Estado, com participação de toda a sociedade.

Ainda no que tange a Sociedade Industrial, e em consonância com o que já foi mencionado ao longo deste trabalho, conforme o avançar do progresso social, da mutabilidade humana e industrial, novos problemas surgiam e assim, novas medidas se viam necessárias a serem tomadas. Neste viés, tendo que nesta época as incertezas quanto às condições de trabalho se mostravam como as mais perversas novidades que incidiam diretamente na economia, Passos (2013, p. 46), menciona que em 1795 foi implantado na Inglaterra, o Speengamland Law, diferente da Poor Law, visto que neste, o indivíduo recebia assistência mesmo quando empregado, se seu salário fosse menor do que a renda familiar estabelecida pela tabela. 


\section{EVOLUÇÃO HISTÓRICA DA PREVIDÊNCIA SOCIAL: o sistema previdenciário \\ brasileiro é estável??}

Contudo, ainda de acordo com o que menciona o autor, este ato não trouxe resultado diferenciado da Poor Law, visto que, apesar da liberdade de locomoção, estas ajudas públicas, associadas ao baixo padrão salarial, desestimulavam qualquer esforço no sentido de buscar trabalho adequado (PASSOS, 2013). Menciona ainda, que em 1834 ocorreu a Reforma da Lei dos Pobres - Poor Law Reform, extinguindo esta forma de auxílio social, no intuito de desobstruir o caminho para a nova economia capitalista e efetivar um mercado de trabalho.

Em suma, na visão de Ibrahim (2015, p. 2 e 3), com o tempo, a assunção por parte do Estado de parcelas de responsabilidade pela assistência aos desprovidos de renda até a criação de um sistema estatal securitário, coletivo e compulsório, pode ser gradativamente notada e evidenciada. Esta rede de segurança estatal, evolui conforme o conceito de Estado evolui, diminuindo a prevalência de conceitos liberais do Estado, de intervenção mínima em áreas fundamentais e adotando conceitos mais intervencionistas, ou seja, trocando o Estado mínimo pelo de 'tamanho certo', conceitos estes sociais-democratas, responsáveis pela construção do Wellfare State, ou Estado do Bem-Estar Social, qual visa justamente a atender outras demandas da sociedade, como a previdência social.

Não obstante, no âmbito dos fatores que teriam demarcado o caminho para o surgimento do Estado Contemporâneo, imprescindível iniciar-se com a Revolução Industrial e seus efeitos sobre a sociedade e a partir dela, em função do ideário liberal do Estado Moderno, fundado no individualismo e liberdade contratual, os problemas gerados pelo trabalho assalariado, concentração de renda e o anseio por uma ruptura com aquele modelo marcado pela exploração do trabalho sem salvaguarda de espécie alguma (CASTRO; LAZZARI, 2015).

A busca pela consolidação do "Estado de tamanho certo", de modo a propiciar uma igualdade de oportunidade para todos, encontrava-se afastado do gigantismo comunista (IBRAHIM, 2015), contudo, convém lembrar que estes conflitos de ideais foram necessários para a construção das ferramentas de proteção social. Seguindo o que menciona Passos (2013, p. 53), a pressão exercida pelos ideais comunistas levou os liberais capitalistas a adotarem medidas políticas, econômicas e sociais a fim de aplacar os ânimos revolucionários e assegurar a manutenção da ordem implantada.

Entrementes, Castro e Lazzari (2015), o intervencionismo estatal toma as feições definitivas no período que vai da quebra da Bolsa de Valores de Nova Iorque, em 1929, ao período imediatamente posterior à Segunda Guerra Mundial, surgindo teorias econômicas 
aliadas a políticas estatais, como o New Deal que moldou o Estado Contemporâneo, sendo neste interregno, onde irá se cunhar a expressão Estado do Bem-Estar Social.

Ante o exposto, tem-se que a proteção social originou-se do consciente humano para com seus semelhantes em tempos ainda remotos, foi gradativamente evoluindo, sendo ampliada e estruturada de modo a estar consolidada nos tempos atuais em textos legais, e em acordo com o que narra Ibrahim no trecho mencionado em sua obra, devendo ser sempre dimensionada com os recursos disponíveis e claro, objetivando o bem maior, o bem estar-social de modo geral.

Por fim, é possível concluir que a proteção social foi evoluindo lentamente e de maneira constante até alcançar o patamar onde está hoje, contudo sendo sempre necessário verificar o contexto histórico para compreender os reais motivos para o desenvolvimento deste conceito, onde, salvo parcas exceções, a proteção de determinados grupos de indivíduos - como os trabalhadores, ocorreram após refletirem de maneira negativa na economia os males que os acometiam ou quando as perdas humanas eram de grande monta.

Sendo assim, conclui-se que devido ás condições de trabalho, proletário e proletariado, eram de fato problemas relevantes ao Estado, economicamente. Assim, tem-se que um dos pilares base para o desenvolvimento do conceito trabalho foram os acontecimentos na seara trabalhista, por assim dizer, desde as épocas remotas, ao período da idade média, industrial, e pós-industrial, somados aos fatos como as guerras mundiais, e demais fatores sociais que instigaram o Estado a modificar sua abordagem frente à sociedade.

\section{EVOLUÇÃO HISTÓRICA MUNDIAL}

A proteção social foi o ponto propulsor de tudo que conhecemos hoje como seguridade social, que engloba a saúde, previdência social e assistência social.

Convém extrair do que narra Horvarth Jr. (2014), que o primeiro sistema de seguro social surge na Prússia, atual Alemanha, tendo caráter nitidamente político, e seu idealizador foi o chanceler - primeiro ministro, Otto Von Bismarck, desenvolvendo este sistema para ganhar a simpatia dos trabalhadores, os quais recebiam forte influência de ideais socialistas na época. Isto seria um reflexo das convulsões sociais retratadas por Castro e Lazzari (2015, p. 910), quais mencionam ainda dois dos grandes influenciadores do que seria o idealismo e movimento socialista da época, como o jurista Lorenz Von Stein, pioneiro no “Estado Social”, 


\section{EVOLUÇÃO HISTÓRICA DA PREVIDÊNCIA SOCIAL: o sistema previdenciário}

brasileiro é estável??

o movimento comunista de Karl Marx e a teoria desenvolvida pelo economista Adolph Wagner, conhecida como a "Lei de Wagner".

Ainda no que narra Horvarth Jr. (2014, p. 24), o sistema de Bismarck foi implantado de modo gradual pelo Parlamento entre os anos de 1883 a 1911, quando neste ano as leis de proteção social foram compiladas com o surgimento do Código de Seguro Social alemão. Esta obra de Otto Von Bismack envolvia seguro-doença, seguro de acidentes do trabalho, seguro de invalidez e proteção à velhice, mediante contribuição do Estado, dos empregados e dos empregadores, iniciando-se aí a tríplice forma de custeio, em prática até hoje (CASTRO; LAZZARI, 2015).

Importante salientar que o Código de Seguro Alemão, lei compilada em 1911, instituía o mencionado caráter contributivo obrigatório, elaborando assim, o sistema de repartição tríplice citado, compondo o modelo de Bismarck, almejando o equilíbrio financeiro do sistema (VIANNA, 2012). Ainda acerca deste modelo de Bismarck, era obrigatória a filiação às sociedades seguradoras ou entidades de socorros mútuos por parte de todos os trabalhadores que recebessem até 2.000 (dois mil) marcos anuais - moeda da época (MARTINS, 2009).

Em 1919 criou-se a Organização Internacional do Trabalho (OIT), sendo esta dotada de característica de órgão internacional, do tipo geral especializada, ou seja, tem por finalidade atuar no âmbito de todos os países em sentido geral, fixando princípios programáticos ou regras imperativas de determinado ramo do conhecimento humano (HORVARTH JR., 2015). Contudo, em 1929 ocorreu a crise da bolsa de valores de nova York, conhecida como a grande depressão econômica, momento em que o presidente Franklin Roosevelt adotou novas políticas sociais com a finalidade de superara-la, inspirando então a doutrina do Welfare State, ou Estado do Bem-Estar Social, conhecidas como New Deal. Esta nova política adotada consistia numa série de medidas nas áreas de saúde, assistência e previdência social, sobretudo no combate ao desemprego, tendo com uma das medidas tomadas, o Social Security Act (VIANNA, 2012). O Social Security Act ajudava os idosos a estimular o consumo, instituindo também o auxíliodesemprego para trabalhadores que temporariamente ficassem desempregados (MARTINS, 2009).

Até esta época, os planos previdenciários (de seguro social), em regra, obedeciam a um sistema chamado bismarckiano, ou de capitalização, ou seja, somente contribuíam os empregadores e os próprios trabalhadores empregados, numa poupança compulsória, 
abrangendo a proteção apenas destes assalariados contribuintes (CASTRO; LAZZARI, 2015). Embora o seguro social fosse imposto pelo Estado, faltava ainda a noção de solidariedade social, visto não haver a participação de todos os indivíduos, finalizam os autores.

Na Inglaterra, no ano de 1941, foi instituído o Plano Beveridge, tendo como seu criador o Lord Beveridge, o qual afirmava que o cidadão deveria ter proteção social do berço ao túmulo, um passo importante na consolidação dos sistemas de seguridade social, isto porque, o plano não visava atender apenas os trabalhadores, mas toda a sociedade, avançando ainda mais na ideia de universalização da seguridade social (VIANNA, 2012). Manteve-se a tríplice forma de custeio, demonstrando assim sua preocupação com o equilíbrio atuarial do sistema e dando possibilidades de vida longa aos planos recém-nascidos.

Então, a partir de 1944, revendo todas as experiências até então praticadas pelos Estados que tinham adotado regimes de previdência, criando um sistema que abrangesse a todos e com participação compulsória de toda a população, tendo a noção de que a seguridade social é o desenvolvimento harmônico dos economicamente debilitados, de modo definitivo, o Plano Beveridge. Assim, nasce o regime beveridgeano, ou de repartição, onde a sociedade num todo contribui para um fundo previdenciário, do qual são retiradas as prestações para aqueles que venham a se enquadrar nos eventos previsto na legislação de amparo social (CASTRO; LAZZARI, 2015).

No Pós-Segunda Guerra mundial, ou seja, após 1945 (a Segunda Guerra Mundial foi entre os anos de 1939 a 1945), nas palavras de Ibrahim (2015, p. 51):

[...] surgiu uma tendência universalizadora do seguro social, com base nas premissas teóricas do Plano Beveridge, devido a elevada taxa de natalidade e crescimento econômico, gerando uma espécie de euforia protetora, com uma universalização da clientela, sem maiores distinções em razão das atividades econômicas, privilegiando a solidariedade, característica chave do Beveridgeanismo.

De acordo com Ibrahim (2015), o financiamento do plano distancia-se da capitalização, com a repartição simples, enfraquecendo o aspecto atuarial do sistema protetivo, visto que no sistema de Beveridge, as prestações pagas pelo sistema são desvinculadas da real remuneração do trabalhador, ao contrário do sistema de Bismarck, onde a prestação é relacionada à cotização.

Não obstante, ainda neste período pós-segunda guerra mundial, a Declaração Universal dos Direitos do Homem, em 1948, inscreveu, entre outros direitos fundamentais da pessoa humana, a proteção previdenciária, mais especificamente no artigo 25 da referida norma 


\section{EVOLUÇÃO HISTÓRICA DA PREVIDÊNCIA SOCIAL: o sistema previdenciário}

brasileiro é estável??

(MARTINS, 2009). Desta forma, a Declaração Universal dos Direitos Humanos contemplou a seguridade social como direito de qualquer pessoa (VIANNA, 2012).

Há que salientar que o modelo previdenciário vislumbrado na política do bem-estar social, o Welfare State, vem sendo substituído, em diversos países, por um outro, no qual o principal fundamento é a poupança individual, sem a centralização dos recursos de contribuições em órgãos estatais, ou seja, a privatização, mantendo alguns, a presença estatal em níveis mínimos, outros, excluindo totalmente o Estado da questão da poupança previdenciária (CASTRO; LAZZARI, 2015). Ademais, cumpre destacar que, conforme menciona Ibrahim (2015), a análise do sistema protetivo deve ser feita dentro do aspecto histórico, onde notamos que até mesmo um posicionamento adotado como o correto pelo Banco Mundial em uma época, teve de ser revisto anos depois.

De modo a abreviar a evolução histórica da seguridade social, Marisa Ferreira dos Santos (2016, p. 29) ressalta que:

[...] a evolução socioeconômica faz com que as desigualdades se acentuem entre os membros da mesma comunidade e da comunidade internacional, tendo uma concentração da maior parte da renda nas mãos de poucos, levando a miséria à maioria, sendo a pobreza um problema social, e não apenas individual [...].

Ainda sobre o tema, Santos (2016) ressalta que o homem por sua vez, sempre se preocupou com a qualidade de sua vida e de sua família, não conseguindo superar situações de enfermidade e desemprego, por exemplo, sozinho, necessitando assim, do amparo do Estado através de instrumentos de proteção, ou seja, a seguridade social.

\section{EVOLUÇÃO HISTÓRICA NO BRASIL}

De modo a iniciar o debate acerca do surgimento da seguridade social no Brasil, Ibrahim (2015, p. 54), menciona que a proteção social seguiu a mesma lógica do plano internacional, origem privada e voluntária, com a formação dos primeiros planos mutualistas e a intervenção do Estado cada vez maior.

Assim, a previdência privada teve origem no Brasil em 1543, quando Braz Cubas criou um plano de pensão para os empregados da Santa Casa de Misericórdia de Santos (VIANNA, 2012). Além disto, Horvarth Jr. (2014, p. 27) relata que a pensão criada abrangia ainda os 
empregados das Ordens Terceiras e outras que mantinham hospitais, asilos, orfanatos e casas de amparo a seus associados e também para os desvalidos.

Em 1793, o Príncipe D. João VI aprovou, em 23 de setembro, o Plano dos Oficiais da Marinha, que vigorou por mais de cem anos, assegurando o pagamento de pensão de meio soldo às viúvas e filhas dos oficiais falecidos, sendo custeada mediante o desconto de um dia de vencimento, qual passava a confundir-se com a Fazenda Real (HORVARTH JR., 2014). Segundo Ibrahim (2015, p. 54), a data da criação do Plano de Benefícios dos Órfãos e Viúvas dos Oficiais da Marinha, foi no ano de 1795, sendo também corroborada esta data na obra de Castro e Lazzari (2015, p. 38).

Anos após, tivemos a Constituição Imperial, em 1824, a qual assegurava socorros públicos, assistência à população carente, contudo, esta previsão constitucional mostrou-se apenas teórica, não tendo sido aplicada de fato na prática, servindo apenas no plano filosófico para remediar a miséria criada pelo dogma da liberdade e igualdade presente na época (HORVARTH JR., 2014). Entrementes, o primeiro texto em matéria de previdência social no Brasil foi expedido em 1821, pelo ainda Príncipe Regente, Dom Pedro de Alcântara, o qual tratava de um Decreto de $1^{\circ}$ de outubro daquele mesmo ano, concedendo aposentadoria aos mestres e professores após 30 anos de serviço, sendo assegurado um abono de $1 / 4$ (um quarto) dos ganhos aos que continuassem em atividade (CASTRO; LAZZARI, 2015).

Em 1835, foi fundado o Montepio Geral dos Servidores do Estado, o MONGERAL, sendo esta a primeira entidade privada organizada de previdência do país, embora sua primeira manifestação tenha sido ainda em 1543, contudo, o MONGERAL contemplava agora modernos institutos de previdência privada (VIANNA, 2012). A criação deste montepio advém ainda do movimento mutualista anterior à lei alemã, tendo esses o ingresso franqueado a qualquer pessoa e sem fins lucrativos, em nada se confundindo com as companhias de seguro, as quais tiveram uma atuação posterior no ramo previdenciário, visando o lucro (IBRAHIM, 2015).

Não obstante, em 1888 tivemos o Decreto $n^{\circ}$. 9.912-A, de 26 de março, qual dispôs sobre a concessão de aposentadoria aos empregados dos correios, fixando em trinta anos de serviço e idade mínima de 60 anos aos requisitos para tal. Logo após, em 1890, tivemos o Decreto $n^{\circ}$. 221, de 26 de fevereiro, instituindo a aposentadoria para os empregados da Estrada de Ferro Central do Brasil, posteriormente estendida aos demais ferroviários do Estado pelo Decreto $\mathrm{n}^{\circ}$. 565, de 12 de julho do mesmo ano (CASTRO; LAZZARI, 2015). Não obstante, ainda no ano de 1888, a Lei $\mathrm{n}^{\circ} 3.397$ havia criado uma Caixa de Socorros em cada uma das 


\section{EVOLUÇÃO HISTÓRICA DA PREVIDÊNCIA SOCIAL: o sistema previdenciário \\ brasileiro é estável??}

Estradas de Fero do Império, além de tratar das despesas gerais da Monarquia para o exercício subsequente (HORVARTH JR. 2014).

Neste processo de evolução da proteção social no Brasil, tivemos em 1891 a promulgação da primeira Constituição brasileira que conteve a expressão “aposentadoria”, qual era então concedida a funcionários públicos em caso de invalidez, contudo, os demais trabalhadores não possuíam qualquer proteção (IBRAHIM, 2015). De fato ainda muito parca em proteção a sociedade em geral, mas em inegável avanço, assim, consolidou no art. 75 da referida Carta Magna, a aposentadoria por invalidez aos servidores públicos (CASTRO; LAZZARI, 2015).

Entrementes, tivemos a edição do Decreto no 10.269 de 20 de junho de 1889, a criação do Fundo Especial de Pensões para os trabalhadores das oficinas da Imprensa Régia, custeada através de um dia de vencimento dos operários, após 30 anos de serviço, tendo direito a uma renda mensal equivalente a 2/3 dos vencimentos médios da função exercida por prazo superior a 24 meses (HORVARTH JR, 2014). Ainda, Ibrahim menciona que no ano de 1890, teve a criação do Montepio obrigatório dos empregados do Ministério da Fazenda por meio do Decreto $\mathrm{n}^{\circ}$. 942-A, de 31 de outubro do referido ano.

Por conseguinte, após a promulgação da Constituição de 1891, no ano de 1892, devido a forte influência dos militares, instituiu-se para os operários do Arsenal da Marinha, a aposentadoria por idade ou invalidez, além da pensão por morte, elencada no Decreto $\mathrm{n}^{0}$. 127, de 29 de novembro de 1892, sendo que este movimento resultou na criação do Seguro de Acidentes de Trabalho no futuro, mais precisamente no ano de 1919 (IBRAHIM, 2015). Sobre as aposentadorias, para Castro e Lazzari (2015, p. 39), estes mencionam que não poderiam ser consideradas como pertencentes a um regime previdenciário contributivo, pois os beneficiários não contribuíam durante o período de atividade, sendo concedidas de certa forma, de forma graciosa pelo Estado. Ou seja, nem se fala em previdência social no Brasil.

Em 1919, através do Decreto Legislativo n 3.724/19, foi criado o seguro de acidente de trabalho no Brasil, sendo este incumbência do empregador, devendo este custear a indenização dos seus empregados, o operário ou suas famílias, em caso de acidentes de trabalho (IBRAHIM, 2015). Narra ainda Ibrahim, que isto ocorria apenas nos casos de força maior ou dolo da própria vítima ou de estranhos, tendo uma sistemática precária, pois não assegurava o pagamento de quantias mensais, mas sim um valor único que oscilava conforme o resultado do evento, tanto 
pela incapacidade quanto a morte. Ressalta Castro e Lazzari (2015, p. 39), que antes deste decreto legislativo, o trabalhador acidentado tinha apenas como norma a lhe proteger o art. 159 do antigo Código Civil, vigente a partir de 1917, e antes ainda, as normas das Ordenações Filipinas.

Já no ano de 1922, em 7 de setembro deste ano, era criada a caixa de Pensões dos Empregados jornaleiros da Estrada de Ferro Central do Brasil, seguindo o modelo da dos Operários da Imprensa Nacional, apenas com benefícios distintos, equivalendo as pensões a 50\% das aposentadorias que teriam direito os contribuintes (HORVARTH JR, 2014).

Em termos de legislação nacional, a doutrina majoritária considera como marco inicial da Previdência Social no Brasil, a publicação do Decreto Legislativo ${ }^{\circ}$. 4.682, de 24 de janeiro de 1923, mais conhecido como Lei Eloy Chaves, criando as Caixas de Aposentadoria e Pensões nas empresas de estradas de ferro existentes, mediante contribuições dos trabalhadores, das empresas do ramo e do Estado - ou seja, forma tríplice de custeio, assegurando aposentadoria aos trabalhadores e pensão a seus dependentes em caso de morte do segurado, além de assistência médica e diminuição do custo de medicamentos (CASTRO; LAZZARI, 2015). A Lei Eloy Chaves encontra suas origens mais remotas na Lei $n^{\circ} .10 .650$ de 14 de maio de 1919, que instituía o seguro social na Argentina (HORVARTH JR., 2014).

Ademais, ainda em 1923 ocorreu a publicação do Decreto $n^{\circ}$. 16.037, criando o Conselho Nacional do Trabalho, com atribuições de decidir sobre questões relativas à Previdência Social, aproximando o Direito do Trabalho com o Direito Previdenciário em ascensão, sendo rompida apenas com a Constituição de 1988, adiantando que o Ministério da Previdência Social só foi apartado do Ministério do Trabalho em 1992 (VIANNA, 2012). Não obstante, a Lei Eloy Chaves foi ampliada pelo Decreto Legislativo $\mathrm{n}^{\circ}$. 5.109/26, estendendo os benefícios das Caixas Às empresas de navegação marítima e fluvial e às de exploração de portos. Insuficiente modificação, em outubro de 1931, o Decreto lei n 20.465 estendeu a todas as classes de empregados em serviço público a proteção previdenciária, assegurando ainda a estabilidade de emprego desde que contasse com mais de dez anos de serviço (HORVARTH JR., 2014).

Acerca da Lei Eloy Chaves, Castro e Lazzari (2015, p. 40) afirmam que esta assemelhasse com o modelo alemão de 1883, visto pelas suas três características fundamentais, como a obrigatoriedade de participação dos trabalhadores no sistema, a contribuição para o sistema devida pelo trabalhador, empregador e pelo Estado, este sendo responsável pela 


\section{EVOLUÇÃO HISTÓRICA DA PREVIDÊNCIA SOCIAL: o sistema previdenciário}

brasileiro é estável??

regulamentação e supervisão do sistema e, por fim, um rol de prestações definidas em lei, a fim de proteger o trabalhador em diversas situações.

Em 1930 tem-se o Decreto 19.554, o qual suspendeu por prazo indeterminado a concessão de aposentadorias ordinárias até advento de nova legislação que corrigisse as falhas apresentadas pela criação desregrada de caixas de pensões e no ano de 1931, o Presidente Getúlio Vargas, estabeleceu através do Decreto $\mathrm{n}^{0}$. 120.465/1931, com força de lei, que as caixas de aposentadoria e pensões fossem agrupadas em institutos profissionais, dando início à proteção previdenciária por categorias (HORVARTH JR., 2014).

Ainda segundo Horvarth Jr. (2014, p. 30), o espaço temporal entre os anos de 1930 a 1940 foi de modificação das caixas de pensões em Institutos de Aposentadoria e Pensões - IAP, as quais tinham forma jurídica de autarquia federal e função de efetivar o controle financeiro, administrativo e diretivo. Tal fato deve-se pela primeira crise do sistema previdenciário, em face de inúmeras fraudes e denúncias de corrupção, forçando o governo Vargas a suspender pelo prazo de seis meses a concessão de qualquer aposentadoria (Decreto $n^{\circ}$. 19.540/30), requerendo revisão geral nos benefícios até ali concedidos (CASTRO; LAZZARI, 2015).

Ibrahim (2015, p. 57) menciona que a unificação das caixas em institutos ampliou a intervenção estatal na área, como os institutos possuíam natureza autárquica e eram subordinados diretamente a União, consolidando-se assim o controle público.

A primeira instituição brasileira de previdências social de âmbito nacional, com base na atividade econômica, foi o Instituto de Aposentadoria e Pensões dos Marítimos, criada em 1933, sendo seguida pela criação dos Comerciários ainda no mesmo ano, dos Bancários em 1934, Industriários em 1936, Instituto de Previdência e Assistência dos Servidores do Estado e IAP dos Empregados em Transportes e Cargas em 1938 (CASTRO; LAZZARI, 2015).

Entrementes, a Constituição Federal de 1934, introduziu novas regras em termos de proteção social, prevendo direitos trabalhistas e previdenciários, fazendo menção expressa aos direitos previdenciários no art. 121, § $1^{\text {o }}$, alínea “h”, do seu texto legal, tendo custeio tripartite, já mencionado anteriormente (HORVARTH JR., 2015). Por sua vez, a Constituição de 1937 não trouxe evoluções na matéria, apenas tendo por particularidade, a utilização pela primeira vez da expressão “seguro social” (CASTRO; LAZZARI, 2015).

O Decreto-Lei de $n^{\circ}$. 7.835/45 estabeleceu que as aposentadorias e pensões não poderiam ser inferiores a 70\% e 35\% do salário-mínimo nacional vigente (VIANNA, 2012). 
Não suficiente, Castro e Lazzari (2015, p. 42) afirmam que a Constituição de 1946 previu normas sobre previdência que versava sobre Direitos Sociais, obrigando o empregador a manter seguro de acidentes de trabalho, sendo esta, então, considerada a primeira tentativa de sistematização constitucional de normas de âmbito social.

Não suficiente, a nova Constituição substituiu a expressão “seguro social” por “previdência social”, avançando na organização do sistema, mantendo ainda, a tríplice contribuição. Ademais, no ano de 1939 foi reorganizado o Conselho Nacional do Trabalho, momento em que foi então criado a Câmara e o Departamento de Previdência Social. Em sequência, ressalta o autor que no ado de 1943 foi publicado o Decreto $n^{\circ}$. 5.452, o qual aprovou a Consolidação das Leis do Trabalho (CLT) e, elaborou também, o primeiro projeto de Consolidação das Leis da Previdência Social (VIANNA, 2012).

Em 1960, foi criado o Ministério do Trabalho e Previdência Social e promulgada

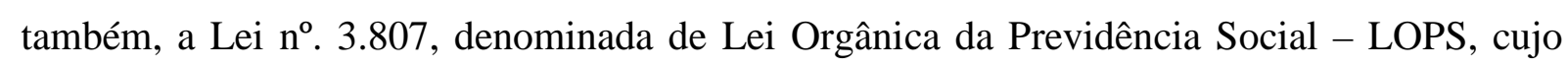
projeto tramitou desde 1947 (CASTRO; LAZZARI, 2015). Este diploma não unificou os organismos existentes como afirma, mas sim, criou normas uniformes para o amparo a segurados e dependentes dos vários Institutos existentes, tendo sido efetivamente colocado em prática, estabelecendo-se um único plano de benefícios. Convém ressaltar que os trabalhadores rurais e domésticos continuavam excluídos da previdência (VIANNA, 2012, p. 13).

Posteriormente, no ano de 1963, houve a criação do salário-família, destinado aos segurados que tivessem filhos menores, visando à manutenção destes, por meio da Lei $n^{\circ}$. 4.296, tendo sido criado neste mesmo ano, o décimo terceiro salário e, pela Lei $\mathrm{n}^{\circ}$. 4.281, o abono anual, até hoje existente (CASTRO E LAZZARI, 2015, p. 43). Neste diapasão, Vianna (2012, p.13), relata que ainda no ano de 1963, criou-se o Fundo de Assistência ao Trabalhador Rural (FUNRURAL), por meio da Lei nº. 4.214.

No transcorrer do tempo, os Institutos de Aposentadoria e Pensões foram unificados pelo Decreto-Lei ${ }^{\circ}$. 72 de 21 de novembro de 1966, qual criou o INPS - Instituto Nacional de Previdência Social (HORVARTH JR., 2014). A consolidação estatal em uma única entidade era justificável, pois a manutenção de vários institutos gerava elevados gastos, sendo redundante pelo fato de exercerem a mesma atividade, além de que alguns trabalhadores mudavam de categoria, exercendo nova atividade, gerando desgaste, quando não, prejuízos financeiros (IBRAHIM, 2015). 


\section{EVOLUÇÃO HISTÓRICA DA PREVIDÊNCIA SOCIAL: o sistema previdenciário}

brasileiro é estável??

Não obstante, a Constituição de 1967 trouxe a redução no tempo de serviço da mulher para trinta anos, quando da aposentadoria integral, inserindo como proteção social constitucionalizada o salário-família e prevendo ainda, a criação do seguro-desemprego (HORVARTH JR., 2014). Ainda em 1967, foi incorporado o Seguro de Acidentes de Trabalho - SAT, à Previdência Social pela Lei ${ }^{\circ}$. 5.136, deixando então de ser realizado com instituições privadas, passando a ser feito com exclusividade por meio de contribuições vertidas ao caixa único do regime geral previdenciário (CASTRO; LAZZARI, 2015).

Convém ressaltar que segundo lembra Ibrahim (2015, p. 59), a Constituição Federal de 1967 foi a primeira a prever o seguro-desemprego, sem outras maiores alterações no regramento previdenciário. Lembra ainda o autor, que as alterações legislativas de 1969 também não trouxeram alterações às previsões previdenciárias do texto constitucional.

Em sequência, no ano de 1971, através da Lei Complementar $n^{0}$ 11, foi instituído o Programa de Assistência ao Trabalhador Rural - PRORURAL, com natureza assistencial, cujo principal benefício era a aposentadoria por idade após 65 anos de idade, equivalente a 50\% do salário mínimo de maior valor no país (IBRAHIM, 2015). Não obstante, a Lei ${ }^{0}$. 5.859/72, incluiu os empregados domésticos como segurados obrigatórios, assim, a Previdência Social brasileira passou a abranger dois imensos contingentes de indivíduos que, embora exercessem atividade laboral, ficavam à margem do sistema (CASTRO; LAZZARI, 2015).

Ainda, em 1974 ocorreu a criação do Ministério da Previdência e Assistência Social, desmembrado do Ministério do Trabalho e Previdência Social, pela Lei $n^{\circ}$. 6.036, e a Lei $n^{\circ}$. 6.125 autorizando o Poder Executivo a constituir a Empresa de Processamento de Dados da Previdência Social - DATAPREV, qual encontra-se em funcionamento até os dias de hoje (VIANNA, 2012). Já em 1977, foi promulgada a Lei nº 6.439, instituindo o SINPAS - Sistema Nacional de Previdência Social, buscando a reorganização da Previdência Social, agregando as entidades como o INPS, o Instituto Nacional de Assistência Médica - INAMPS, DATAPREV, Fundação Nacional do Bem-Estar do Menor - FUNABEM, Fundação Legião Brasileira de Assistência - LBA, Instituto de Administração Financeira da Previdência Social - IAPAS e Central de Medicamentos - CEME (IBRAHIM, 2015).

Neste sentido, cumpre ressaltar o que lembra Vianna (2012, p. 13), ao mencionar que neste mesmo ano de 1974 foi publicada a Lei $\mathrm{n}^{\circ}$. 6.179, a qual instituiu o amparo previdenciário 
para maiores de 70 anos ou inválidos, sendo este amparo conhecido como a renda mensal vitalícia.

O SINPAS - Sistema Nacional de Previdência Social, teve como atribuições a concessão e manutenção de benefícios e prestação de serviços, custeio de atividade e programas e gestão administrativa, financeira e patrimonial (HORVARTH JR., 2014). Foi possível ainda observar certa confusão entre os conceitos de previdência social, assistência social e saúde pública, quando da criação do SINPAS, pois houve uma paliação do sentido de previdência social, abarcando também a assistência social (CASTRO; LAZZARI, 2015).

Também foi esta mesma lei que criou o Instituto Nacional de Assistência Médica da Previdência e Social - INAMPS e o Instituto de Administração Financeira da Previdência e Assistência Social - IAPAS, ambos integrados à estrutura do SINPAS (IBRAHIM, 2015). Ainda neste sentido, Ibrahim (2015) discorre que à época da criação da SINPAS, a legislação previdenciária vigente era a LOPS, sendo que era difícil tratar a matéria previdenciária devido a existência de diversos diplomas legais, assim, o art. $6^{\circ}$ da Lei $n^{\circ}$. 6.243/75 determinou ao Poder Executivo a expedição, por decreto, de Consolidação das Leis da Previdência Social CLPS, refeita anualmente, sem alteração substantiva da matéria legal.

Neste diapasão, extrai-se da obra de Ibrahim (2015, p. 61), que o Executivo foi encarregado de reunir as legislações previdenciárias por meio de decreto, em um mesmo corpo legislativo, o que seria algo próximo a criação de um Código Previdenciário. Assim, de acordo com o autor, pelo Decreto $\mathrm{n}^{\circ}$. 77.077, de 24 de janeiro de 1976, foi feita a primeira CLPS que não sofreu revisões anuais, posteriormente, uma nova foi publicada por meio do Decreto ${ }^{\circ}$. 89.312/84, deixando esta última de ser aplicada apenas com o advento da Lei ${ }^{\circ}$. 8.213, em 1991.

Sob o mesmo diapasão, ainda neste ano de 1991, foi também publicada a Lei $n^{\circ}$. 8.212, a qual por sua vez dispunha acerca da organização da Seguridade Social Brasileira e instituiu o Plano de Custeio (VIANNA, 2012). No ano seguinte, em 1992, Vianna lembra a criação do Ministério da Previdência Social por intermédio da Lei $\mathrm{n}^{\circ}$. 8.422 e da Lei ${ }^{\circ}$. 8.540 que dispôs sobre a contribuição do empregador rural para a Seguridade Social.

Em 1995, através da Medida Provisória $n^{\circ}$. 813/95, foi criado o Ministério da Previdência e Assistência Social, sendo que em 1993, foi publicada a Lei nº . 8.742, a qual dispôs sobre a organização da Assistência Social, também conhecida como LOAS (Lei Orgânica da Assistência Social). Não obstante, a Constituição da República Federativa do Brasil de 1988, 


\section{EVOLUÇÃO HISTÓRICA DA PREVIDÊNCIA SOCIAL: o sistema previdenciário}

brasileiro é estável??

tratou pela primeira vez, da Seguridade Social, entendida esta como um conjunto de ações nas áreas de Saúde, Previdência e Assistência Social (IBRAHIM, 2015), sendo ela evidente marca do Estado de bem-estar social criado pelo constituinte de 1988.

Castro e Lazzari (2015, p. 49) narram que no final do ano legislativo de 1998, foi promulgada a proposta da Emenda Constitucional $n^{\circ}$. 20, de iniciativa do Presidente da República, a qual tramitava desde 1995.

Ainda de acordo com os autores, outro aspecto que merece ser ressaltado é o de que na data subsequente à promulgação da referida Emenda Constitucional nº 20 de 1998, em 15 de dezembro de 1998, a idade mínima para o ingresso na condição de trabalhador e então, segurado, da Previdência, passou a ser 16 (dezesseis) anos, salvo na condição de aprendiz, a partir de 14 (quatorze) anos. Ademais, aos segurados menores de 16 anos já filiados ao Regime Geral de Previdência Social até essa data, são assegurados todos os direitos previdenciários, com base no Decreto n ${ }^{\circ}$. 3.048/99 (CASTRO; LAZZARI, 2015).

Atualmente, convém destacar que o Regulamento da Previdência Social anteriormente mencionado, corresponde ao Decreto $n^{\circ}$. 3.048/99, que regulamenta as disposições relativas ao custeio da seguridade e aos benefícios da previdência social, bem como, com suas alterações subsequentes (IBRAHIM, 2015).

Em momentos posteriores ao da promulgação da Constituição de 1988, elenca Vianna (2012, p. 15), outras alterações legislativas que ocorreram no ramo previdenciário, como o Decreto acima mencionado, em vigor até hoje, a Lei $\mathrm{n}^{\circ}$. 10.421/02, estendendo à mãe adotiva o direito à licença-maternidade e ao salário-maternidade, alterando a Consolidação das Leis do Trabalho e a Lei $n^{\circ}$. 8213/91, bem como, a Lei $n^{\circ} .10 .683$ de 2003 que criou o Ministério da Assistência Social, removendo esta atividade do Ministério da Previdência Social. Ainda, em 2005, veio a Lei $n^{\circ}$. 11.098 que criou a Secretaria da Receita Previdenciária no Âmbito do Ministério da Previdência Social.

Entrementes, convém ressaltar que ainda em 1990 foi criado o Instituto Nacional do Seguro Social - INSS, autarquia que substituiu o INPS e o IAPAS nas funções de arrecadação, bem como pagamento de benefícios e prestação de serviços aos segurados e dependentes do RGPS (CASTRO; LAZZARI, 2015). A arrecadação, fiscalização, cobrança de contribuições, aplicação de penalidades e regulamentação da matéria direcionada ao custeio da Seguridade Social mencionadas por Castro e Lazzari (2015, p. 47), foram transferidas para a Secretaria da 
Receita Federal do Brasil, órgão do Ministério da Fazenda, oriunda da fusão da Secretaria da Receita Federal com a Secretaria da Receita Previdenciária, por meio da Lei nº. 11.457/07 (VIANNA, 2012).

Não obstante, em 1999 foi publicada a Lei de nº 9.876, momento em que ao invés de adotar-se a idade mínima para aposentadoria voluntária no Regime Geral de Previdência Social, foi adotada uma forma de cálculo que leva em consideração a idade do segurado, o tempo de contribuição deste e a expectativa de sobrevida da população brasileira, sendo este cálculo chamado de "fator previdenciário" (CASTRO; LAZZARI, 2015). Sob este diapasão, Castro e Lazzari (2015, p. 53) elegem outra inovação apresentada por esta mesma lei citada, que foi a nova forma de cálculo dos benefícios de prestação continuada sendo apurados com base na noção de salário benefício (aposentadorias, pensões, auxílios-doença, e auxílios-acidente).

Em 2008 a Lei Complementar 128/2008 revogou, dentre outros, os arts. 45 e 46 da Lei $n^{\circ}$. 8.212/91 e em 2008, a Lei $n^{\circ} .11 .770$ instituiu o Programa Empresa Cidadã, destinado a prorrogar por 60 (sessenta) dias a duração da licença maternidade. Neste mesmo ano, foi promulgada a Lei $\mathrm{n}^{\circ} .11 .718$, criando o contrato de trabalhador rural por pequeno prazo, além de estabelecer normas transitórias sobre a aposentadoria do trabalhador rural e alterando as Leis $n^{\circ}$. 8.212/91 e 8.213/91 (HORVARTH JR, 2014).

Dentre as demais doutrinas aqui utilizadas, Horvarth Jr (2015, p. 54-62) foi o mais completo em relação a elencar as legislações posteriores à 2007, como:

[...] o Decreto $\mathrm{n}^{\circ} .6 .727 / 2008$, a Lei $\mathrm{n}^{\circ} .12 .023 / 09$, a Lei $\mathrm{n}^{\circ} .12 .190 / 10$, a importante
Lei de $\mathrm{n}^{\circ} .12 .435 / 11$ que alterou a LOAS, já citada previamente, dando nova redação
a alguns artigos, bem como elencou as Leis de $\mathrm{n}^{\circ}$. $12.440 / 11,12.618 / 12$ (instituiu o
regime de previdência complementar aos servidores públicos federais de cargo
efetivo) e a Lei $\mathrm{n}^{\circ} .12 .692 / 12$ (alterou os arts. 32 e 80 da Lei $\mathrm{n}^{\circ} .8 .212 / 91$ ). Além
destas, o autor menciona o que descreveu a Emenda Constitucional de $\mathrm{n}^{\circ} 72 / 2013$,
alterando o art. $7^{\circ}$ da Constituição Federal assegurando aos domésticos os direitos
elencados em alguns dos incisos do referido artigo, bem como sua integração à
previdência social, além de lembrar da Lei Complementar $\mathrm{n}^{\circ}$. $142 / 2013$, a qual
regulamentou o $\S 1^{\circ}$ do art. 201 da CF/88, no que tange a aposentadoria da pessoa
com deficiência segurada do RGPS [...].

Atualmente, estamos vivendo novamente um período de mudanças na previdências social, com a PEC - Projeto de Emenda Constitucional n. 287/2016 ${ }^{i}$ tramitando no Congresso Nacional, a qual visa reformar o sistema previdenciário.

Entre as mudanças previstas na PEC 287/2016 temos a alteração da idade mínima para aposentaria por idade, extinção da aposentadoria por tempo de contribuição, alteração do 


\section{EVOLUÇÃO HISTÓRICA DA PREVIDÊNCIA SOCIAL: o sistema previdenciário}

brasileiro é estável??

período de carência, alterações no benefício da pensão por morte, alteração dos requisitos da aposentadoria do segurado especial, fim do fator previdenciário e criação de uma regra de transição.

A partir das alterações vivenciadas no sistema previdenciário brasileiro, percebe-se que não se trata de um sistema estável, sofrendo alterações constantes para fins de garantir o equilíbrio atuarial e a garantia da solidariedade social.

\section{CONCLUSÃO}

A partir do presente artigo conseguiu-se verificar a evolução histórica do direito social à previdência tanto em âmbito global, quanto em âmbito nacional.

Percebe-se que a proteção social tem origem na natureza humana de ajudar os que enfrentam contingências mundanas, que acometem o homem de maneira alheia a sua vontade, sendo transposta do plano subconsciente e intuitivo, ao plano racional e assim, positivado. Desta forma, o homem criou, vagarosamente, instrumentos que foram abarcando o conceito da proteção social em um formato de regulamentos, originando assim a seguridade social, e também, a previdência social.

A existência de alterações nos textos constitucionais e legais relacionados à previdência social correspondem a uma violação irrisória do princípio da vedação ao retrocesso social, que faz-se necessária a partir da ponderação entre princípios constitucionais e previdenciários, valendo-se da relativização daquele em detrimento de outros como a reserva do possível e o equilíbrio atuarial e financeiro do Estado, além do mínimo existencial.

Caso ocorra uma aparente violação do princípio da vedação do retrocesso social, esta estará ocorrendo com base na ponderação com outros princípios constitucionais, de modo a consagrar a efetividade, de fato, das garantias fundamentais sociais ao indivíduo e à sociedade

Os preceitos fundamentais não são absolutos e é possível relativizar o princípio da vedação ao retrocesso, fazendo com que o Estado consiga resguardar não apenas a tutela das garantias individuais, mas sim, os direitos sociais no âmbito da sociedade. O direito não pode ser imutável, visto que para o futuro da sociedade e do Estado, não podem ser ignoradas as questões demográficas e econômicas. 


\section{REFERÊNCIAS BIBLIOGRÁFICAS}

BRASIL, Constituição da República Federativa do Brasil de 1988. Diário Oficial da União, Brasília, DF, 5 out. $1988 . \quad$ Disponível em: <http://www.planalto.gov.br/ccivil_03/constituicao/constituicaocompilado.htm>. Acesso em: 3 jul. 2017.

. Constituição (1988). Emenda Constitucional n. 20, de 15 de dezembro de 1998. Modifica o sistema de previdência social, estabelece normas de transição e dá outras providências. Diário Oficial da União, Brasília, DF, 16 dez. 1998. Disponível em: < http://www.planalto.gov.br/ccivil_03/constituicao/emendas/emc/emc20.htm>. Acesso em: 3 jul. 2017.

. Decreto n. 3.048, de 6 de maio de 1999, que aprova o Regulamento da Previdência Social e dá outras providências. Diário Oficial da União, Brasília, DF, 7 maio 1999. Disponível em: <http://www.planalto.gov.br/ccivil_03/decreto/d3048.htm>. Acesso em: 3 jul. 2017.

Exposição de motivos n. 23, da medida provisória no ${ }^{0}$ 664, de 30 de dezembro de 2014. Disponível em: <http://www2.camara.leg.br/legin/fed/medpro/2014/medidaprovisoria664-30-dezembro-2014-779852-exposicaodemotivos-145823-pe.html>. Acesso em: 3 jul. 2017.

Lei n. 8.080, de 19 de setembro de 1990, que dispõe sobre as condições para a promoção, proteção e recuperação da saúde, a organização e o funcionamento dos serviços correspondentes e dá outras providências. Diário Oficial da União, Brasília, DF, 20 set. 1990. Disponível em: <http://www.planalto.gov.br/ccivil_03/leis/L8080.htm >. Acesso em: 3 jul. 2017.

Lei n. 8.212, de 24 de julho de 1991, que dispõe sobre a organização da Seguridade Social, institui o Plano de Custeio, e dá outras providências. Diário Oficial da União, Brasília, DF, 25 jul. $1991 . \quad$ Disponível em: <http://www.planalto.gov.br/ccivil_03/leis/L8212cons.htm>. Acesso em: 3 jul. 2017.

. Lei n. 8.213, de 24 de julho de 1991, que dispõe sobre os planos de benefícios da previdência social e dá outras providências. Diário Oficial da União, Brasília, DF, 25 jul. 1991. Disponível em: <http://www.planalto.gov.br/ccivil_03/leis/L8213cons.htm>. Acesso em: 3 jul. 2017.

Lei n. 8.742, de 7 de dezembro de 1993, que dispõe sobre a organização da Assistência Social e dá outras providências. Diário Oficial da União, Brasília, DF, 8 dez. 1998. Disponível em: <http://www.planalto.gov.br/ccivil_03/leis/L8742.htm >. Acesso em: 3 de jul. 2017.

Lei n. 13.135, de 17 de junho de 2015, que altera Altera as Leis no 8.213, de 24 de julho de 1991, no 10.876, de 2 de junho de 2004, no 8.112, de 11 de dezembro de 1990, e no 10.666, de 8 de maio de 2003, e dá outras providências. Diário Oficial da União, Brasília, DF, 18 jun. 2015. Disponível em: <http://www.planalto.gov.br/ccivil_03/_ato20152018/2015/lei/l13135.htm>. Acesso em: 3 jul. 2017.

. Medida Provisória n. 664, de 30 de dezembro de 2014. Altera as Leis no 8.213, de 24 de julho de 1991, $n^{\circ} 10.876$, de 2 junho de 2004, $n^{\circ}$ 8.112, de 11 de dezembro de 1990, e a Lei no 10.666, de 8 de maio de 2003. Diário Oficial da União, Brasília, DF, 30 dez. 2014. 
Disponível em: $<\quad$ http://www.planalto.gov.br/ccivil_03/_Ato20112014/2014/Mpv/mpv664.htm>. Acesso em: 3 jul. 2017.

CASTRO, C. A. P. de.; LAZZARI, J. B. Manual de Direito Previdenciário. $18^{\mathrm{a}}$ ed. rev. atual. e ampl. Rio de Janeiro: Forense, 2015.

HORVARTH JR., M. Direito previdenciário. $10^{\mathrm{a}}$ ed. rev. e ampl. São Paulo: Quartier Latin, 2014.

IBRAHIM, F. Z. Curso de direito previdenciário. $21^{\text {a }}$ ed. rev. ampl. e atual. Rio de Janeiro: Impetus, 2015.

MARTINS, S. P.; MORAES, A. (Coord.). Direito da seguridade social. 10 $0^{\text {a }}$ ed. São Paulo: Atlas, 2009.

PASSOS, F. L. dos. Previdência social e sociedade pós-industrial. Curitiba: Juruá, 2013.

SANTOS, M. F.; LENZA, P. (Coord.). Direito previdenciário esquematizado. 6ed. São Paulo: Saraiva, 2016.

VIANNA, J. E. G. Curso de direito previdenciário. 5ª ed. São Paulo: Atlas, 2012.

\footnotetext{
i Disponível em http://www.camara.gov.br/proposicoesWeb/fichadetramitacao?idProposicao=2119881, acesso em 08 abr 2018.
} 